\section{Phenanthroline Covalent Organic Framework Electrodes for High-Performance Zinc-Ion Supercapattery}

\author{
Wenxi Wang, Vinayak S. Kale, ${ }^{\ddagger}$ Zhen Cao, ${ }^{\ddagger}$ Sharath Kandambeth, Wenli Zhang, Jun Ming, \\ Prakash T. Parvatkar, Edy Abou-Hamad, Osama Shekhah, Luigi Cavallo, Mohamed Eddaoudi,* \\ and Husam N. Alshareef*
}

Cite This: ACS Energy Lett. 2020, 5, 2256-2264

Read Online

ACCESS | Lلll Metrics \& More | 回 Article Recommendations

S1 Supporting Information

ABSTRACT: Aqueous zinc-ion batteries and capacitors are potentially competitive grid-scale energy storage devices because of their great features such as safety, environmental friendliness, and low cost. Herein, a completely new phenanthroline covalent organic framework (PA-COF) was synthesized and introduced in zinc-ion supercapatteries (ZISs) for the first time. Our as-synthesized PA-COF shows a high capacity of $247 \mathrm{mAh}$ $\mathrm{g}^{-1}$ at a current density of $0.1 \mathrm{~A} \mathrm{~g}^{-1}$, with only $0.38 \%$ capacity decay per cycle during 10000 cycles at a current density of $1.0 \mathrm{~A} \mathrm{~g}^{-1}$. Although covalent organic frameworks (COFs) are attracting great attention in many fields, our PA-COF has been synthesized using a new strategy involving the condensation reaction of hexaketocyclohexanone and 2,3,7,8-phenazinetetramine. Detailed mechanistic investigations, through experimental and theoretical methods, reveal that the phenanthroline

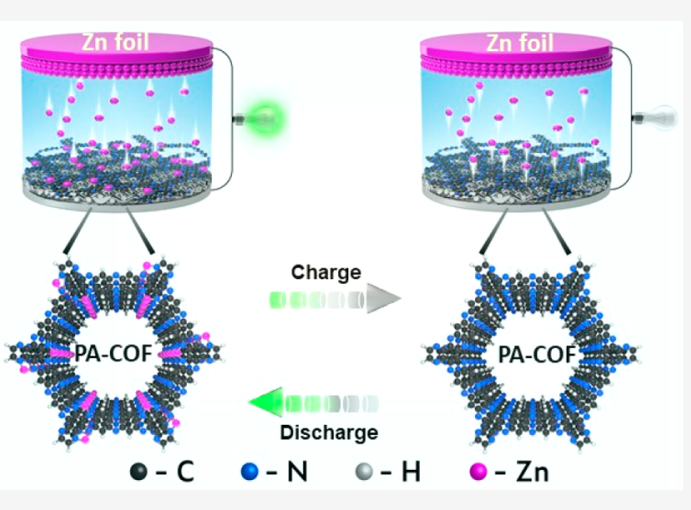
functional groups in PA-COF are the active zinc ion storage sites.

Furthermore, we provide evidence for the cointercalation of $\mathrm{Zn}^{2+}(60 \%)$ and $\mathrm{H}^{+}(40 \%)$ into PA-COF using inductively coupled plasma atomic emission spectroscopy and deuterium solid-state nuclear magnetic resonance (NMR). We believe that this study opens a new avenue for COF material design for zinc-ion storage in aqueous ZISs.

$\mathrm{Z}$ inc-ion supercapatteries (ZISs) are promising energy storage devices among the monovalent $\left(\mathrm{Li}^{+}, \mathrm{Na}^{+}\right.$, and $\left.\mathrm{K}^{+}\right)$and multivalent metal-ion $\left(\mathrm{Mg}^{2+}, \mathrm{Ca}^{2+}\right.$, and $\left.\mathrm{Al}^{3+}\right)$ batteries because of their high safety, nontoxicity, and relatively low cost. ${ }^{1-3}$ More efforts are being exerted to develop diverse cathode materials for aqueous ZISs such as manganese-based and $^{4,5}$ vanadium-based oxides, ${ }^{6-8}$ as well as Prussian blue analogues (PBAs). ${ }^{9}$ Herein, we report a completely new phenanthroline covalent organic framework (PA-COF), which was synthesized and used as a ZIS cathode. As we know, COFs are an emerging class of organic polymers with periodic skeletons constructed by spatially stitching organic building blocks via strong covalent linkage. ${ }^{10,11}$ COFs not only have a reticular $\pi$-conjugated backbone but also possess a permanent porosity and crystallinity due to their topological architecture. The highly crystalline $\pi$-conjugated backbone of COF provides a stable chemical and physical reaction environment, which is particularly useful for the long-term operation at variable cathodic and anodic polarizations. ${ }^{12}$ In fact, although many COFs with different topological skeletons have been synthesized $^{13-15}$ for application in energy storage, ${ }^{16-19}$ catalysis, $^{20,21}$ sensors, $^{22}$ gas storage, ${ }^{23}$ etc., detailed studies of the electrochemical behavior of COF as cathodes in aqueous ZIS has seldom been mentioned to date. Moreover, it has been reported that there still remains a great challenge to design a chemically and thermally stable polymeric electrode material, with rich nucleophilic centers for electrophilic $\mathrm{Zn}^{2+}$ ion acceptor. $^{24}$

The design of PA-COF we report here was inspired by the modular nature of COFs, which can be adjusted by tailoring an electron-rich backbone with heteroatoms at the molecular level. For example, it has been reported that nitrogen substitution in 1,4,5,8-naphthalenetetracarboxylic dianhydride (NTCDA) can improve the specific capacity and cycling

Received: April 27, 2020

Accepted: June 8, 2020

Published: June 8, 2020

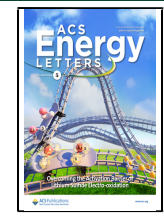



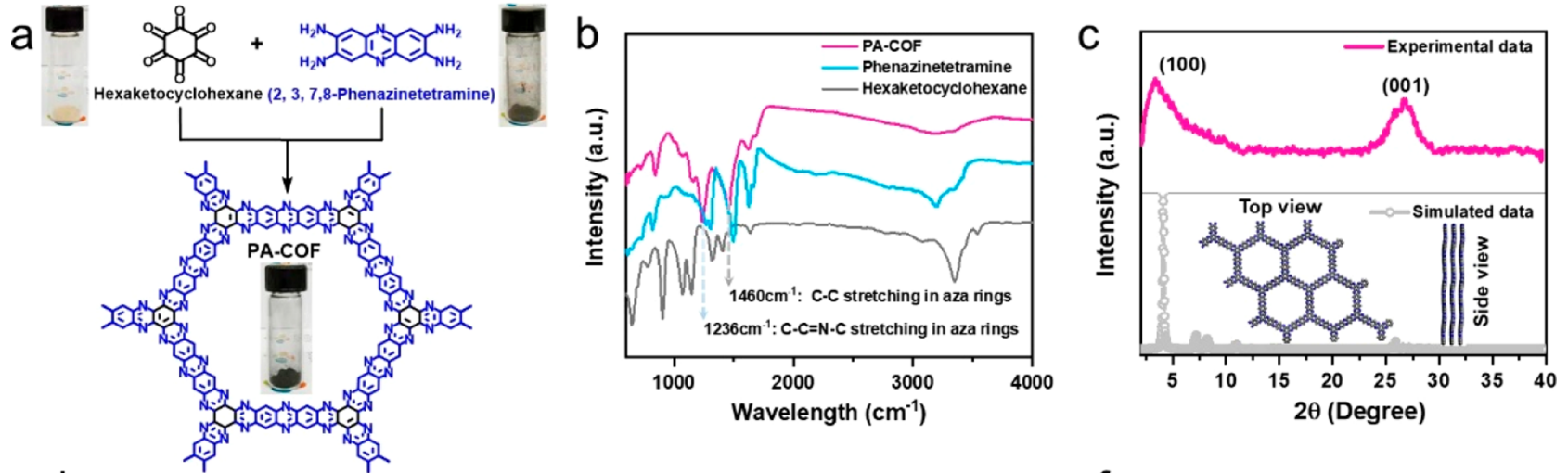

d

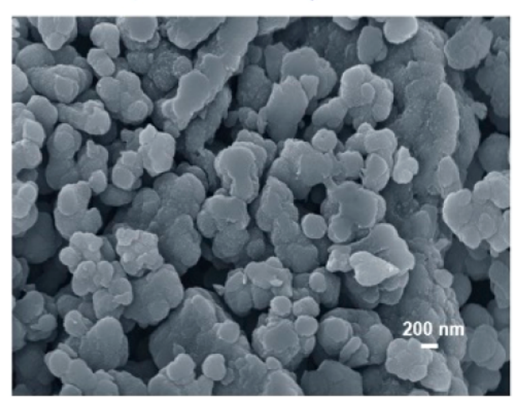

e

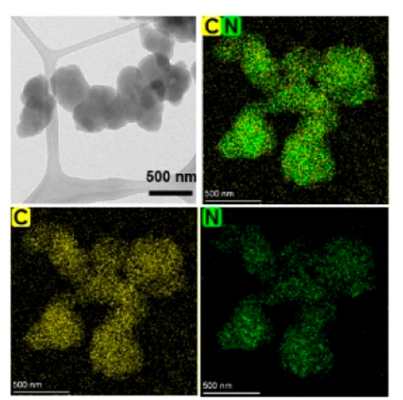

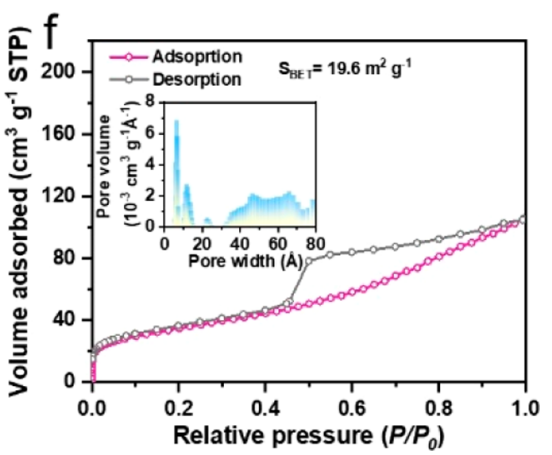

Figure 1. Synthesis and characterization of the as-synthesized PA-COF. (a) Illustration of the synthetic route for PA-COF. (b) Comparative FT-IR spectra of the precursors and PA-COF. (c) Powder X-ray diffraction pattern (PXRD). (Inset is the top and side view of the AA eclipsed model.) (d) Scanning electron microscopy (SEM) image and (e) transmission electron microscopy (TEM) images with elemental mapping of PA-COF. (f) Nitrogen adsorption-desorption isotherm and inset showing pore-size distributions of PA-COF.

stability of NTCDI electrode in zinc-ion batteries (ZIBs). ${ }^{25}$ It has also been reported that nitrogen-doping in hierarchical porous carbon can promote the chemical adsorption of $\mathrm{Zn}^{2+}$ ions. ${ }^{26}$ Thus, we anticipated that PA-COF with electron-rich backbone and rich nitrogen active sites, as well as the medium pore size of $2-5 \mathrm{~nm}$, might facilitate the reversible mobile ion intercalation. As a result, we have developed and tested this new PA-COF as cathode in ZISs. We demonstrate a high capacity of $247 \mathrm{mAh} \mathrm{g}^{-1}$ at a current density of $0.1 \mathrm{~A} \mathrm{~g}^{-1}$, with only $0.38 \%$ capacity decay per cycle during 10000 cycles at a current density of $1.0 \mathrm{~A} \mathrm{~g}^{-1}$. We further extensively studied the intercalation mechanism of PA-COF in aqueous zinc ion supercapatteries by experimental and theoretical methods and found it to involve cointercalation of $\mathrm{Zn}^{2+}(60 \%)$ and $\mathrm{H}^{+}$ (40\%). We believe that this study opens a new avenue for COF material design and application in zinc-ion storage in aqueous electrolytes.

The synthetic process of PA-COF is presented in Figure 1a, which involves a solvothermal condensation reaction of hexaketocyclohexane and 2, 3, 7, 8-phenazinetetramine. The as-synthesized PA-COF is a novel 1,4,5,8,9,12 -hexaazatriphenylene (HAT) derivative ${ }^{27}$ that introduces nitrogen-rich phenanthroline units into the conjugated and rigid aromatic framework. The incorporation of the phenanthroline structure was confirmed by the emergence of Fourier transform infrared spectroscopy (FT-IR) peaks at 1236 and $1460 \mathrm{~cm}^{-1}$ (Figure $1 \mathrm{~b})$, which corresponds to the stretching of $\mathrm{C}-\mathrm{C}=\mathrm{N}-\mathrm{C}$ and $\mathrm{C}-\mathrm{C}$ from the aza rings. ${ }^{28}$ The carbon backbone of PA-COF was verified by ${ }^{13} \mathrm{C}$ solid-state NMR (Figure S1, Supporting Information). The sharp peak with chemical shifts around 138.1 and $109.5 \mathrm{ppm}$ can be assigned to carbon from $\mathrm{C}-\mathrm{C}=\mathrm{N}$ and $\mathrm{C}=\mathrm{C}-\mathrm{C}$, respectively (Figure $\mathrm{S} 1$, peaks $\mathrm{b}$ and $\mathrm{d}$, Supporting Information). Another two broad peaks around
152.6 and $130.1 \mathrm{ppm}$ can be ascribed to the carbon from N$\mathrm{C}-\mathrm{C}$ and $\mathrm{C}=\mathrm{C}-\mathrm{N}$, respectively (Figure $\mathrm{S} 1$, peaks a and $\mathrm{c}$, Supporting Information). ${ }^{29}$ This difference in FT-IR and ${ }^{13} \mathrm{C}$ solid-state NMR results confirms the successful preparation of PA-COF and the formation of its rigid conjugated frameworks. Additionally, the thermal stability of as-synthesized PA-COF material was confirmed by the thermogravimetric analysis (TGA) in argon gas (Figure S2, Supporting Information). We find that the weight loss in PA-COF is only $10 \%$ when the temperature was increased to $600{ }^{\circ} \mathrm{C}$. In contrast, the hexaketocyclohexane and phenazinetetramine precursors show a weight loss of $85 \%$ and $30 \%$ at $600{ }^{\circ} \mathrm{C}$, respectively. The higher thermostability of PA-COF compared with its precursors confirms the formation of rigid conjugated frameworks. In addition, two broad peaks at $3.4^{\circ}$ and $26.7^{\circ}$ can be observed in the powder X-ray diffraction (PXRD) profile of as-synthesized PA-COF (Figure 1c), which can be assigned to (100) and (001) planes. The PXRD result demonstrates the periodic structure of PA-COF. Particularly, the broad peak around $26.7^{\circ}$ is mainly due to $\pi-\pi$ stacking construction, revealing the existence of a multilayered COF structure with an interlayer distance of $3.34 \AA$. The simulated PXRD patterns of the inset model with an eclipsed orientation (inset in Figure 1c: AA eclipsed model) match well with the experimental results (another two simulated results are shown in Figure S3, and the corresponding crystallographic parameters are shown in Table S1, Supporting Information). The morphology variation of scanning electron microscopy (SEM) images from precursor to as-synthesized COF further verifies the reaction product is PA-COF. The as-synthesized PA-COF is made up of globular particles with diameters around $300 \mathrm{~nm}$ (Figure 1d), which is totally different from the irregular morphologies of the precursors and confirms its 
a

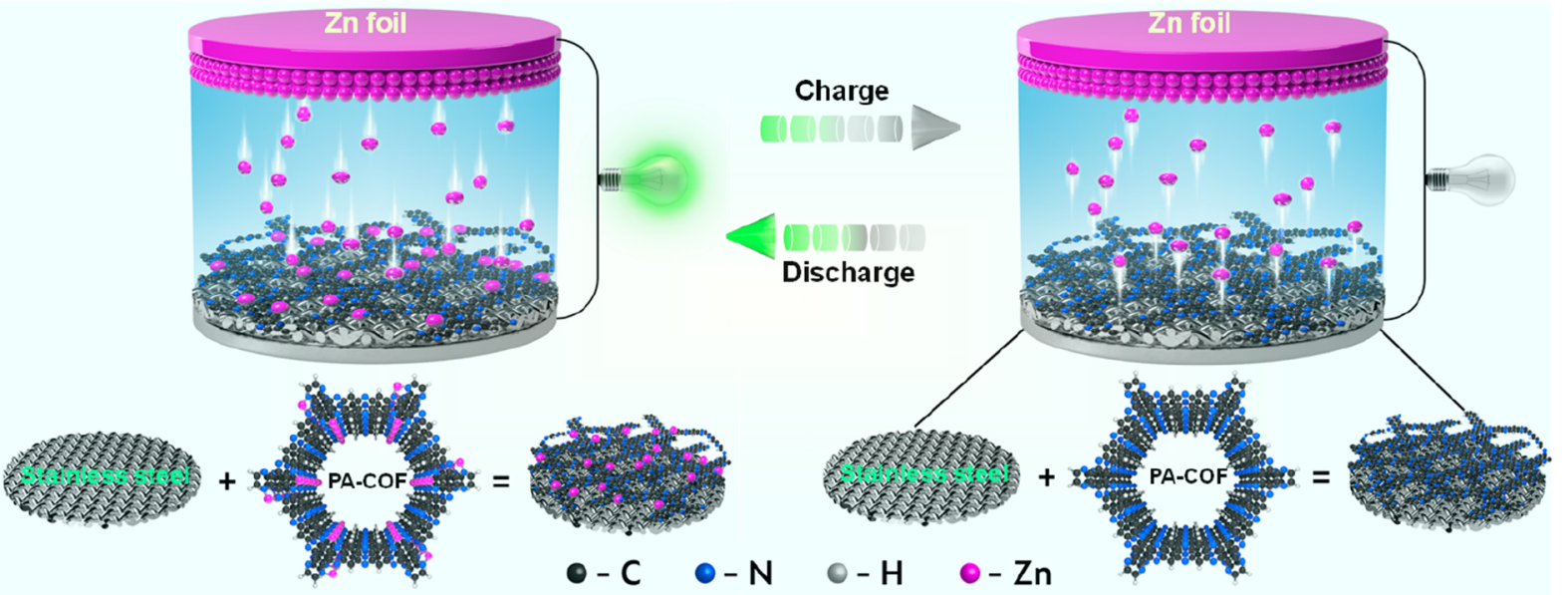

b

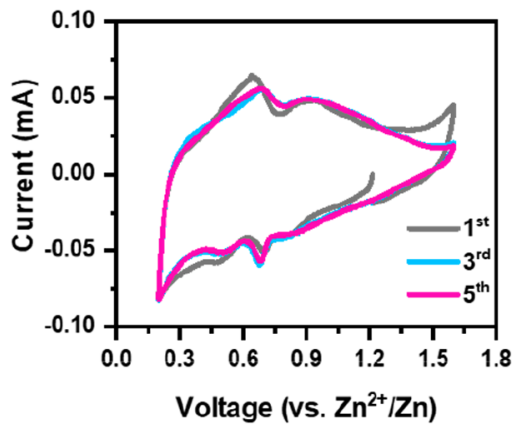

e

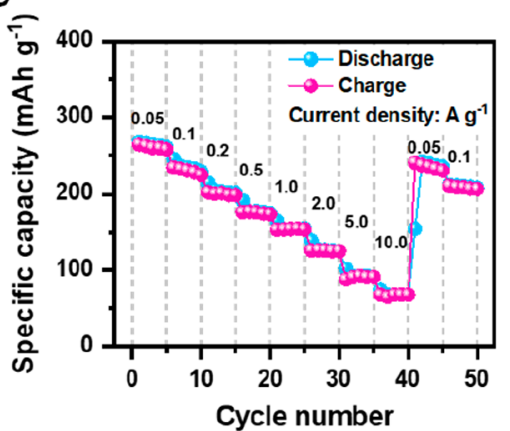

C
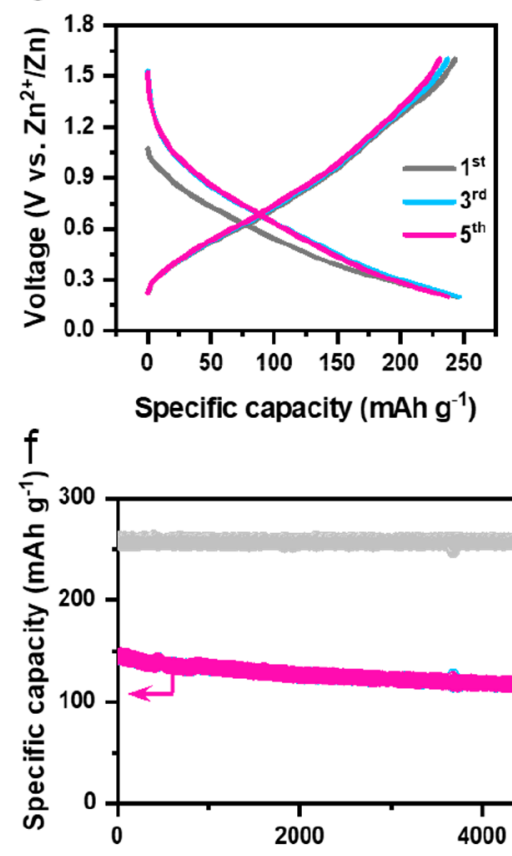

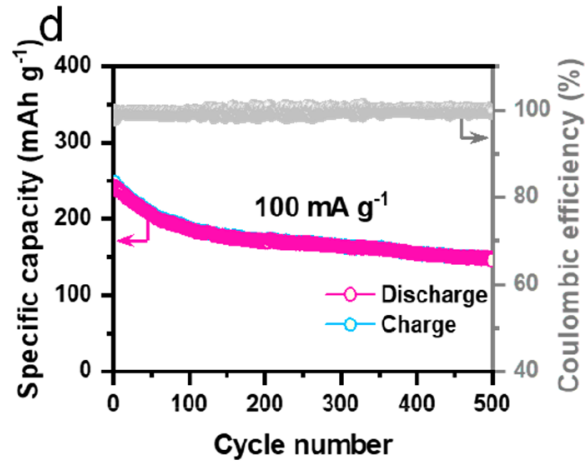

Figure 2. Schematic illustration of zinc ion supercapattery (ZIS) and electrochemical performance. (a) Schematic configuration of PA-COFll 1.0 $\mathrm{M} \mathrm{ZnSO}_{4} \| \mathrm{Zn}$ metal ZIS. Electrochemical behavior of PA-COF in $1.0 \mathrm{M} \mathrm{ZnSO}_{4}$ electrolyte within a potential window of $0.2-1.6 \mathrm{~V}$. (b) Cyclic voltammetry (CV) curves at a scan rate of $0.05 \mathrm{mV} \mathrm{s}^{-1}$. (c) (Dis-) charge profiles and (d) Galvanostatic cycling performance at a current density of $0.1 \mathrm{~A} \mathrm{~g}^{-1}$. (e) Rate performance measured in the current range of $0.05-10 \mathrm{~A} \mathrm{~g}^{-1}$. (f) Long-term cycling stability at a current density of $1.0 \mathrm{~A} \mathrm{~g}^{-1}$.

formation (Figure S4a,b, Supporting Information). The uniform elemental distribution of $\mathrm{C}$ and $\mathrm{N}$ in transmission electron microscopy (TEM) images also demonstrates the homogeneous nature of PA-COF (Figure 1e). In addition, the specific surface area is $19.6 \mathrm{~m}^{2} \mathrm{~g}^{-1}$ and the mesoporous character with a pore size of $2-5 \mathrm{~nm}$ in PA-COF was calculated from the IV-type isotherms (Figure 1f). Such a low surface area and mesoporous nature account for the chemical interaction of ions with host COF material, instead of a simple physical adsorption, as will be discussed later.

The structure of the aqueous ZIS using PA-COF cathode and $\mathrm{Zn}$ anode in $1.0 \mathrm{M} \mathrm{ZnSO}_{4}$ electrolyte is presented in Figure $2 \mathrm{a}$, showing a variation of PA-COF during the discharge and recharge process. The reversibility of the PA-COF cathode in the ZIS can be evaluated directly from the CV profiles as shown in Figure $2 \mathrm{~b}$. We observe two pairs of redox peaks around $0.69 / 0.48 \mathrm{~V}$ and $0.64 / 0.93 \mathrm{~V}$, which correspond to the variation of redox states of COF upon the (de)insertion of ions coupled with electron transfer in the PA-COF skeleton. Furthermore, the CV profiles are almost overlapped after the first, third, fifth, and tenth cycles at the scan rate of $0.1 \mathrm{mV} \mathrm{s}^{-1}$ as shown in Figure S5, implying the electrochemical stability of the PA-COF electrode. The high capacity of PA-COF can be observed in the galvanostatic (dis-)charge curves, where a capacitive-like charge-storage behavior without the obvious voltage plateau ${ }^{24}$ was demonstrated with a high capacity of 247 $\mathrm{mAh} \mathrm{g}^{-1}$ (Figure 2c). The superior cycling performance is further demonstrated at a current density of $0.1 \mathrm{~A} \mathrm{~g}^{-1}$ (Figure $2 \mathrm{~d}$ ), where the retained capacity was as high as $175 \mathrm{mAh} \mathrm{g}^{-1}$ after 300 cycles. The capacity decay in the initial hundred cycles might result from the formation of byproducts (e.g., $\left.\mathrm{Zn}_{4}(\mathrm{OH})_{6} \mathrm{SO}_{4} \cdot 5 \mathrm{H}_{2} \mathrm{O}\right)$ at a low current density, which is a 

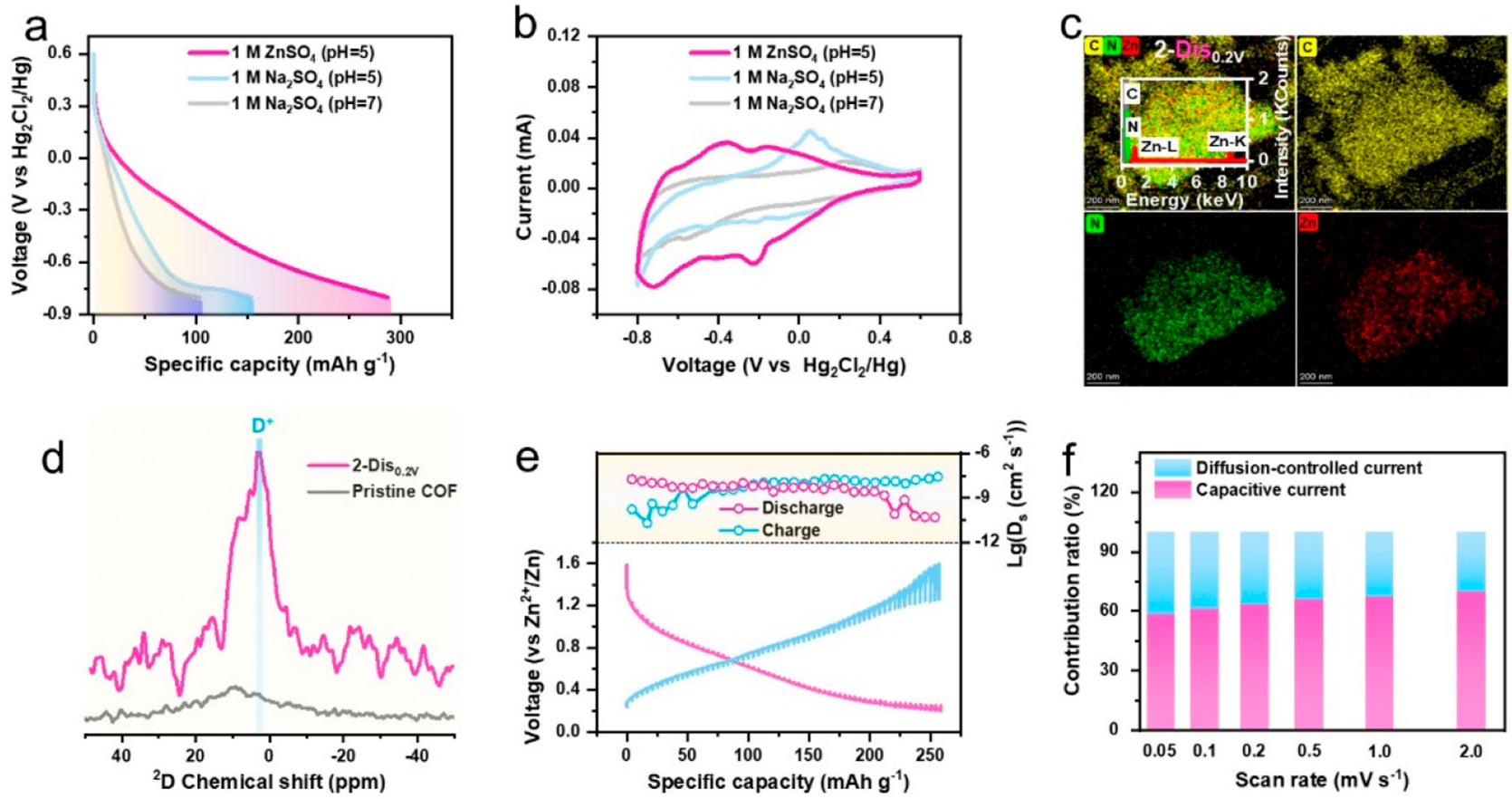

Figure 3. Charge storage mechanism investigation in PA-COF cathode of ZIS. (a) Discharge curves of the second cycle at a current density of $0.05 \mathrm{~A} \mathrm{~g}^{-1}$ and (b) $\mathrm{CV}$ profiles at a scan rate of $0.05 \mathrm{mV} \mathrm{s}^{-1}$ in different electrolytes tested in three-electrode system. (c) TEM elemental mapping images after the second discharge. (d) Comparative deuterium $\left({ }^{2} \mathrm{D}\right)$ solid-state NMR spectra. (e) Galvanostatic intermittent titration techniques (GITT) curves and calculated diffusion coefficients of PA-COF during cycling under $0.02 \mathrm{~A} \mathrm{~g}^{-1}$. (f) Capacitive and diffusion-controlled capacity contribution at different scan rates.

common phenomenon in aqueous zinc-ion batteries (ZIBs). ${ }^{30}$ However, such a high capacity in our devices is due to the chemical intercalation of ions coupled with electron transfer on the active sites of PA-COF, rather than the capacity from an electric double layer. This is because PA-COF shows a specific area of only $19.6 \mathrm{~m}^{2} \mathrm{~g}^{-1}$, whereas the specific capacity stored through physical absorption-desorption (electric double layer) should be proportional to the specific area (Table S2). ${ }^{26}$ Further, we will present a detailed analysis of the storage mechanism of $\mathrm{Zn}^{2+}$ and $\mathrm{H}^{+}$in the PA-COF which is dominated by the intercalation process in the subsequent section. Figure $2 \mathrm{e}$ shows that the rate capability of the PA-COF electrode, where capacities of $265,234,202,176,153,125,93$, and 68 $\mathrm{mAh} \mathrm{g}^{-1}$ were obtained at a current densities of $0.05,0.1,0.2$, $0.5,1.0,2.0,5.0$, and $10 \mathrm{~A} \mathrm{~g}^{-1}$, respectively. The capacity recovers to 240 and $210 \mathrm{mAh} \mathrm{g}^{-1}$ when the current was switched back to 0.05 and $0.1 \mathrm{~A} \mathrm{~g}^{-1}$, respectively. More importantly, a remarkable cycling stability was achieved with only $0.38 \%$ capacity decay per cycle within 10000 cycles at a current density of $1.0 \mathrm{~A} \mathrm{~g}^{-1}$ (Figure 2f). Additionally, the particle morphology of the PA-COF electrode after 100 cycles at a current density of $1.0 \mathrm{~A} \mathrm{~g}^{-1}$ shows only minor changes compared to the pristine sample, indicating a stable framework of the PA-COF material (Figure S6a,b). This cycling stability is the best that has been reported for the COF material in zinc ion batteries or capacitors.

Herein, the charge storage mechanism of PA-COF in aqueous ZIS was analyzed through the various physicochemical techniques. The electrochemical behaviors of PA-COF electrode in 1.0 $\mathrm{M} \mathrm{Na}_{2} \mathrm{SO}_{4}(\mathrm{pH}=7), 1.0 \mathrm{M} \mathrm{Na}_{2} \mathrm{SO}_{4}(\mathrm{pH}=5)$, and $1.0 \mathrm{M} \mathrm{ZnSO}_{4}(\mathrm{pH}=7)$ electrolytes were tested, separately. Three different discharged curves were observed. We find that the specific capacity of the PA-COF electrode in $1.0 \mathrm{M} \mathrm{ZnSO}_{4}$ electrolyte is much greater (i.e., $270 \mathrm{mAh} \mathrm{g}^{-1}$ ) than that in 1.0 $\mathrm{M} \mathrm{Na}_{2} \mathrm{SO}_{4}(\mathrm{pH}=7)$ and $1.0 \mathrm{M} \mathrm{Na}_{2} \mathrm{SO}_{4}(\mathrm{pH}=5)$ electrolytes (Figure 3a). These comparative results demonstrate that the $\mathrm{Zn}^{2+}$ intercalation is dominant, even though the radius of hydrated $\mathrm{Zn}^{2+}$ (i.e., $0.43 \mathrm{~nm}$ ) is larger than that of hydrated $\mathrm{Na}^{+}(0.358 \mathrm{~nm})$ and $\mathrm{H}^{+}(0.1 \mathrm{~nm})$ ions. ${ }^{3,31,32}$ The intercalation of $\mathrm{Zn}^{2+}$ is further confirmed by the cyclic voltammogram (CV) measurement in the different electrolytes (Figure $3 \mathrm{~b}$ ). We find that the $\mathrm{CV}$ curve in $1.0 \mathrm{M} \mathrm{ZnSO}_{4}$ electrolyte shows the largest integral area, implying the highest specific capacity among the three electrolytes. This is consistent with the highest discharge capacity seen in Figure 3a. In addition, two pairs of reductionoxidation broad peaks can be observed within a potential window of $-0.8-0.6 \mathrm{~V}$ ( $\mathrm{vs} \mathrm{Hg}_{2} \mathrm{Cl}_{2} / \mathrm{Hg}$ ). The profiles and number of redox peaks are apparently different from those in $1.0 \mathrm{M} \mathrm{Na}_{2} \mathrm{SO}_{4}(\mathrm{pH}=7)$ and $1.0 \mathrm{M} \mathrm{Na} \mathrm{SO}_{4} \quad(\mathrm{pH}=5)$ electrolytes. In addition, strong evidence for $\mathrm{Zn}^{2+}$ intercalation into PA-COF can be observed from the comparative TEM and SEM mapping images after discharge and charge processes. The $\mathrm{Zn}$ signal can be clearly observed in the electrode after the second discharge (Figure 3c), whereas the $\mathrm{Zn}$ signal is not easy to observe in the electrode after the second recharge (Figure S7, Supporting Information). The same variation can be observed in the SEM mapping images (Figure S8a-b, Supporting Information). These results show that reversible $\mathrm{Zn}^{2+}$ (de)intercalation within the PA-COF electrode does indeed take place.

Solid-state NMR was used to further analyze the possible proton intercalation in PA-COF electrodes that were discharged to $0.2 \mathrm{~V}$ in deuterium oxide electrolyte. We find that only one $\mathrm{D}_{2} \mathrm{O}$ peak around $8.6 \mathrm{ppm}$ can be observed in the pristine electrode, whereas an additional chemical peak around $3 \mathrm{ppm}$ appears in the electrode after the second discharge 

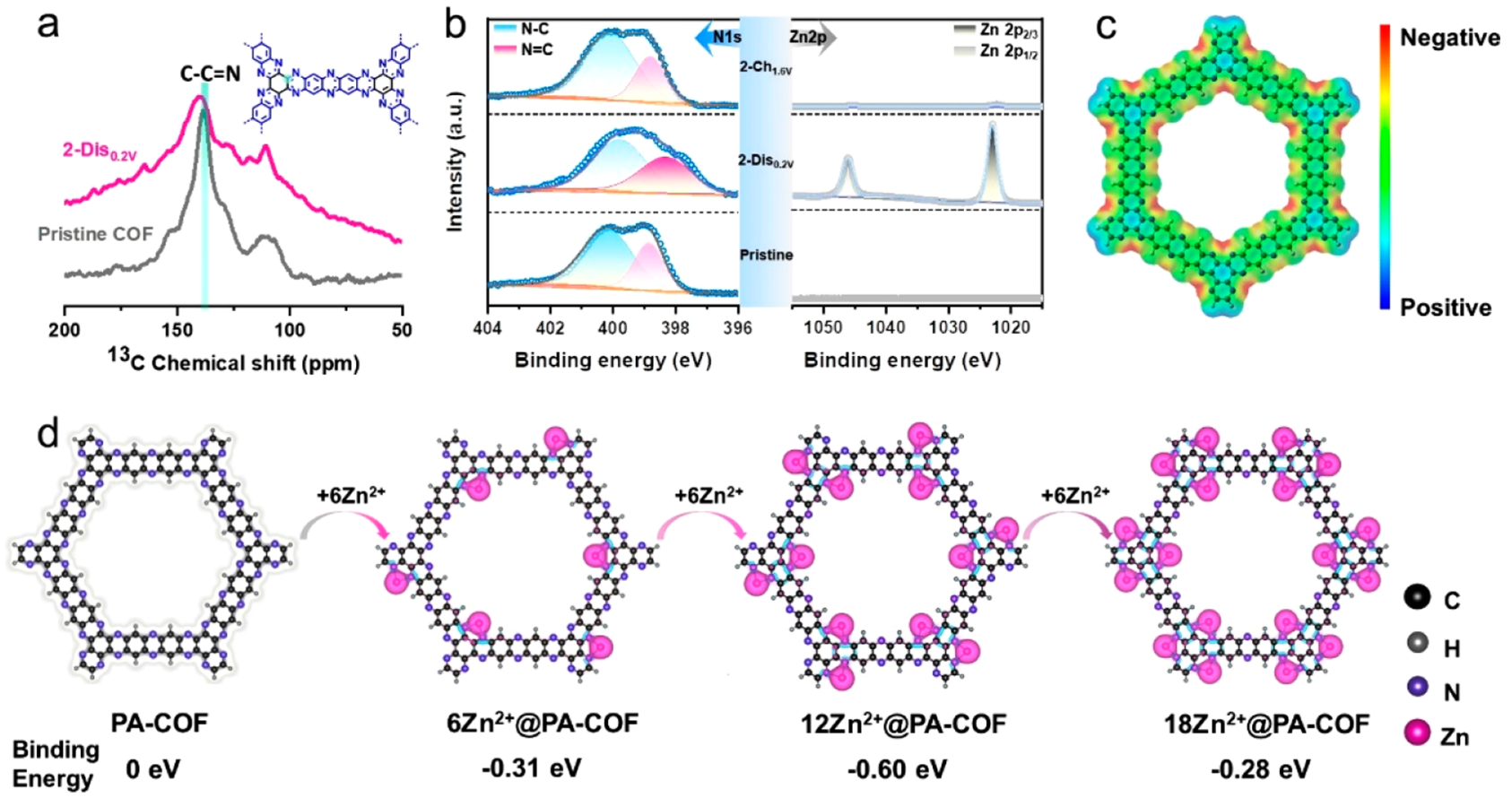

Figure 4. (a) Comparative ${ }^{13} \mathrm{C}$ solid-state NMR spectra of pristine and discharged PA-COF electrodes. (b) N 1s X-ray photoelectron spectroscopy (XPS) of PA-COF electrode in the pristine and discharge-recharge states and the corresponding Zn 2p XPS. (c) Electronegativity simulation of PA-COF. (d) Simulation of binding energies with different numbers of $\mathrm{Zn}^{2+}$ in PA-COF.

(Figure 3d). This can be attributed to the presence of $\mathrm{D}^{+}$ions in the PA-COF cathodes, which was confirmed by spin relaxation studies as shown in Figure S9 (Supporting Information). The ${ }^{2} \mathrm{D}$ spin-lattice relaxation $\left(T_{1}\right)$ can be fitted with three components. The two short relaxations $(0.423$ and $0.479 \mathrm{~s})$ can be assigned to component $1\left(\mathrm{D}^{+}\right)$and 2 $\left(\mathrm{OD}^{-}\right)$, respectively. The very short time relaxation $(0.423 \mathrm{~s})$ is due to ionic charges of deuterium. In contrast, the composite 3 shows a much longer $T_{1}$ around $6.4 \mathrm{~s}$, which can be assigned to $\mathrm{D}_{2} \mathrm{O}$. As a result, these data suggest the existence of $\mathrm{D}^{+} /$ $\mathrm{OD}^{-}$and $\mathrm{D}_{2} \mathrm{O}$ in the electrode (inset table in Figure S9, Supporting Information), which proves that proton intercalation takes place in aqueous ZISs. In addition, the ion diffusion coefficient of the PA-COF electrode was calculated to be around $10^{-8}-10^{-11} \mathrm{~cm}^{2} \mathrm{~s}^{-1}$ (Figure $3 \mathrm{e}$ ), where the magnitude of the diffusion coefficient is similar to those in reported literature, ${ }^{33,34}$ further confirming the $\mathrm{Zn}^{2+} / \mathrm{H}^{+}$cointercalation mechanism within PA-COF. In addition, the charge storage kinetics of the PA-COF electrode was quantitatively analyzed to detect the capacity contribution of $\mathrm{Zn}^{2+}$ and $\mathrm{H}^{+}$in $1.0 \mathrm{M}$ $\mathrm{ZnSO}_{4}$ electrolyte using a three-electrode setup. As is wellknown, the charge storage commonly involves the surface capacitive effects and diffusion-controlled intercalation process. ${ }^{35}$ In this case, $70 \%$ of capacitive current is obtained at a scan rate of $2.0 \mathrm{mV} \mathrm{s}^{-1}$ (Figure S10, Supporting Information). The capacitive contribution at a scan rate from 0.05 to $2.0 \mathrm{mV}$ $\mathrm{s}^{-1}$ is further identified in Figure 3f, which displays a gradual increase of capacitive current from $59 \%$ to $70 \%$. These results imply a capacitive-like surface-controlled process of the PACOF electrode in aqueous ZISs, which explains the high rate capabilities.

Electrochemical impedance spectroscopy (EIS) was used to differentiate the electrochemical phenomenon caused by the intercalation of different ions (Figure S11, Supporting Information). All EIS curves are mainly composed of a semicircle (charge-transfer resistance, $R_{\mathrm{ct}}$ ) and slope line (ionic diffusion resistance) at the medium- and low-frequency ranges (Figure S11, Supporting Information). Initially, the fresh PACOF electrode shows almost the same shape of semicircles in 1.0 $\mathrm{M} \mathrm{Na}_{2} \mathrm{SO}_{4}(\mathrm{pH}=7)$, $1.0 \mathrm{M} \mathrm{Na}_{2} \mathrm{SO}_{4}(\mathrm{pH}=5)$, and $1.0 \mathrm{M}$ $\mathrm{ZnSO}_{4}$ electrolyte except for a slightly higher $R_{\mathrm{ct}}$ resistance values in the $1.0 \mathrm{M} \mathrm{Na}_{2} \mathrm{SO}_{4}(\mathrm{pH}=5)$ electrolyte. However, the electrode shows a noticeable difference in $R_{\mathrm{ct}}$ after the 10th cycle in different electrolytes, indicating different Faradaic reactions in the PA-COF electrode. ${ }^{36}$ This is caused by the intercalation of different ionic species, including $\mathrm{Na}^{+}, \mathrm{Na}^{+} / \mathrm{H}^{+}$, and $\mathrm{Zn}^{2+} / \mathrm{H}^{+}$intercalation, respectively. Furthermore, a longer charge-transfer time constant was measured for the PA-COF electrode in 1.0 $\mathrm{M} \mathrm{ZnSO}_{4}$, further confirming the $\mathrm{Zn}^{2+}$ intercalation process in the PA-COF material (Table S3, Supporting Information).

The active sites for the ion storage in PA-COF were further detected by ${ }^{13} \mathrm{C}$ solid-state NMR, where the peak evolution of pristine and discharged sample is shown in Figures 4a and S12. Three groups of peaks can be observed, for which an obvious chemical shift occurs at the carbon in the $\mathrm{C}-\mathrm{C}=\mathrm{N}$ group (i.e., from 138.1 to $140.9 \mathrm{ppm}$ ). This should be ascribed to the deshielding effect, ${ }^{24}$ which is triggered by $\mathrm{Zn}^{2+} / \mathrm{H}^{+}$intercalation coupled with an electron-transfer process on the covalent scaffold. This result strongly manifests the chemical reaction between the active sites and $\mathrm{Zn}^{2+} / \mathrm{H}^{+}$ions during the discharge process. The reaction sites for $\mathrm{Zn}^{2+} / \mathrm{H}^{+}$intercalation in PA-COF were further analyzed by $\mathrm{X}$-ray photoelectron spectroscopy (XPS) as shown in Figure $4 \mathrm{~b}$. We find that the pristine and the charged electrodes display two well-separated $\mathrm{N}$ 1s peaks in Figure $4 \mathrm{~b}$, whereas the discharged electrode shows only a broad $\mathrm{N} 1 \mathrm{~s}$ peak and high $\mathrm{Zn} 2 \mathrm{p}$ signal (Figure $4 \mathrm{~b})$. This variation in $\mathrm{N}$ ls peak is clearly correlated with the $\mathrm{Zn}^{2+} / \mathrm{H}^{+}$intercalation process that occurs during the discharge cycle. The binding energy of $\mathrm{N}=\mathrm{C}(398.9 \mathrm{eV})$ and $\mathrm{N}-\mathrm{C}$ 

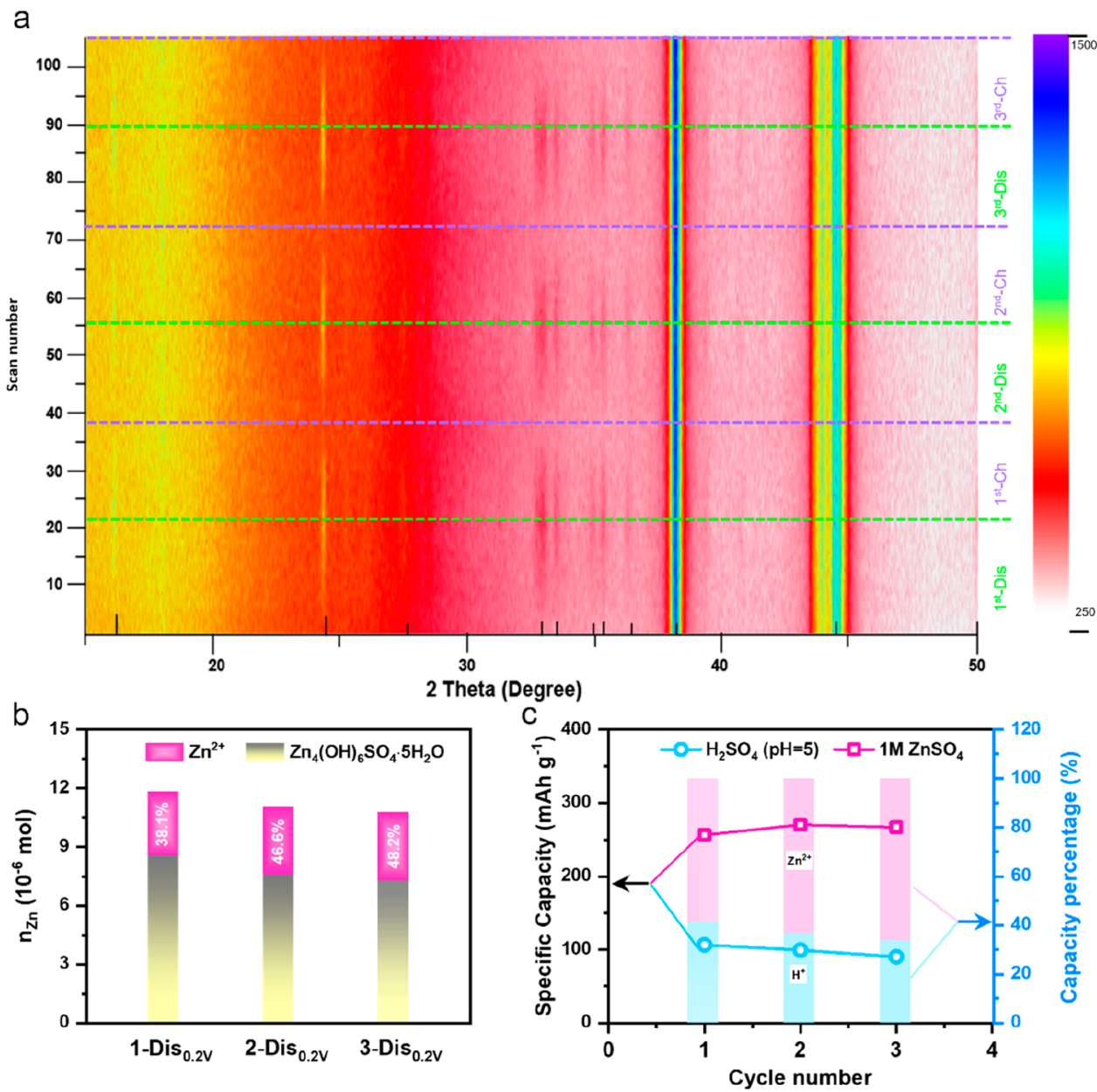

Figure 5. (a) In itu XRD mapping of PA-COF during the first three cycles in $1.0 \mathrm{M} \mathrm{ZnSO}_{4}$ electrolyte. (b) Zinc percentage calculated from $\mathrm{Zn}^{2+}$ and $\mathrm{Zn}_{4}(\mathrm{OH})_{6} \mathrm{SO}_{4} \cdot 5 \mathrm{H}_{2} \mathrm{O}$ (ZOHS) during the first three discharge cycles. (c) Quantitative analysis of $\mathrm{Zn}^{2+}$ and $\mathrm{H}^{+}$contributions to capacity.

a

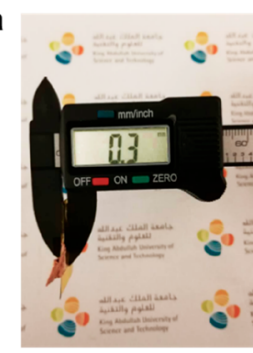

c

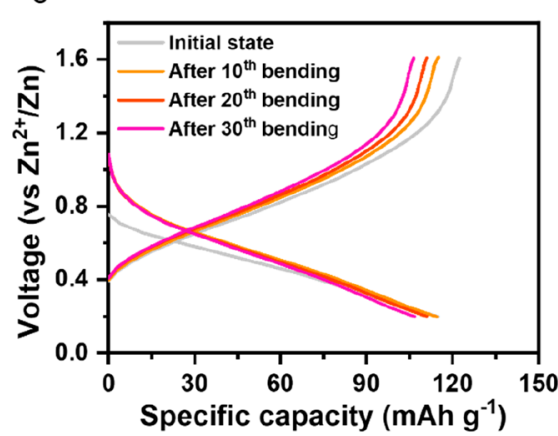

b

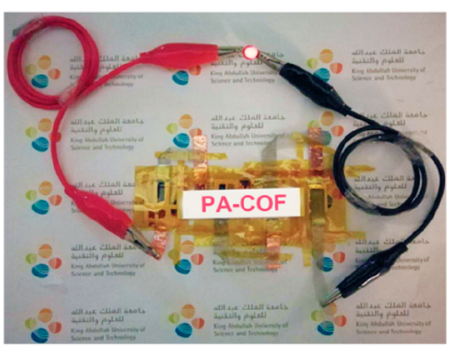

d

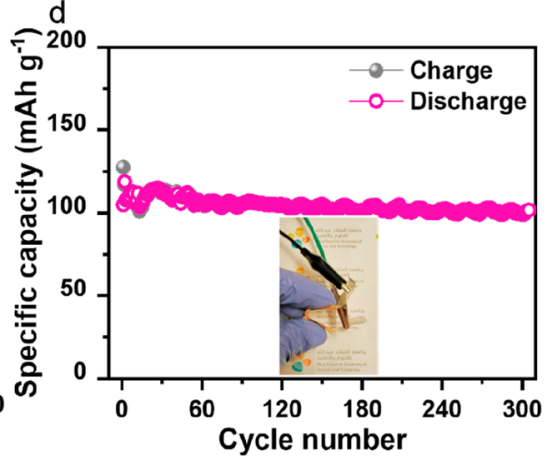

Figure 6. Flexible supercapattery fabricated using PA-COF cathodes. (a) Thickness and bending measurements. (b) Digital image of $1.5 \mathrm{~V}$ LED light powered by tandem ZISs. (c) (Dis-)charge curves at initial state and after bending. (d) Cycling performance under repeated bending conditions. 
$(400.2 \mathrm{eV})^{37}$ in the pristine electrode is slightly decreased to 398.4 and $399.7 \mathrm{eV}$ after the electrode is discharged to $0.2 \mathrm{~V}$. The binding energy then returns to the initial state after the electrode is recharged to $1.6 \mathrm{~V}$. Accordingly, the electrochemical active sites for $\mathrm{Zn}^{2+} / \mathrm{H}^{+}$binding within the PA-COF skeleton were confirmed by the electrostatic potential surface (EPS) in Figure 4c, as shown in the red region near the corner nitrogen of two nearby phenanthroline rings. The reddish EPS indicates strong chemical affinity for cation coordination. The binding energies of PA-COF bonded with 6, 12, and $18 \mathrm{Zn}^{2+}$ are negative in Figure $4 d$, indicating the efficient utilization of the nitrogen sites and a relatively large capacity for zinc batteries. Thus, the hexagonal 2D lattice with phenanthroline unit enriched with negative EPS region can efficiently host cations, such as $\mathrm{Zn}^{2+} / \mathrm{H}^{+}$, within the channels of the PA-COF.

The identification of the capacity contribution from $\mathrm{Zn}^{2+}$ and $\mathrm{H}^{+}$in the PA-COF material is important to understand for the intercalation mechanism. We analyzed the reaction products in the first three (dis-)charge process by in situ Xray diffraction (Figure 5a) patterns. A regular variation of the intense peaks at $16.2^{\circ}(002)$ and $24.3^{\circ}(003)$ can be found during the (dis-)charge process, mainly indicating the formation of the triclinic crystal phase $\mathrm{Zn}_{4}(\mathrm{OH})_{6} \mathrm{SO}_{4} \cdot 5 \mathrm{H}_{2} \mathrm{O}$ (ZOHS) (PDF no. 39-0688). This result is consistent with the SEM and elemental mapping images in Figure S8 (Supporting Information), where plenty of zinc hydroxide sulfate flakes can be observed. The growth of ZOHS nanoflakes primarily results from the increased $\mathrm{OH}^{-}$concentration near the cathode, which also reflects the intercalation of $\mathrm{H}^{+}$. A quantitative analysis of zinc and sulfur elements after the (dis-)charge process was then run using inductively coupled plasma atomic emission spectroscopy (ICP-AES). We find that 38.1\%, 46.6\%, and $48.2 \% \mathrm{Zn}^{2+}$ is presented in PA-COF electrode, which accounts for $54.5 \%, 61.3 \%$, and $60.0 \%$ of the total capacity in the first three cycles, respectively (Figure $5 \mathrm{~b}$ and Table S4, Supporting Information). In this case, this analysis of ICP-AES indicates that the rest of the capacity contribution should be from $\mathrm{H}^{+}$. We further confirm the capacity contributions through capacity measurement in the pure $1.0 \mathrm{M} \mathrm{ZnSO}_{4}$ and $\mathrm{H}_{2} \mathrm{SO}_{4}$ ( $\mathrm{pH} 5$ ) electrolyte, respectively (Figure 5c). The results show a $\mathrm{Zn}^{2+}$ intercalation of $59.3 \%, 63.3 \%$, and $66 \%$, which is consistent with the capacity contribution calculated from ICPAES results.

A high-performance flexible supercapattery was designed and fabricated for practical applications. The flexible supercapattery has a thickness of $0.3 \mathrm{~mm}$ and can be bent to around $120^{\circ}$ (Figure 6a), demonstrating a robust construction. The value of the open-circuit voltage $(\mathrm{OCV})$ is $1.16 \mathrm{~V}$, which is almost identical to that of the coin-cell type supercapattery (Figure S13, Supporting Information). This result demonstrates the reproducibility of the COF electrodes and batteries. A tandem battery was fabricated to achieve a higher voltage for the specific applications, such as lighting the 1.5 V LED lamp (Figure 6b, Video S1, Supporting Information). The flexible devices demonstrated a high stability under the bending conditions (Figure $6 \mathrm{c}, \mathrm{d}$ ). We find that the (dis-)charge profiles are very similar after the bending test, excluding a slight capacity decay (Figure 6c). The cycling measurement indicates that the flexible device tends to be stable after a small capacity fluctuation in the initial 60 cycles at $1.0 \mathrm{~A} \mathrm{~g}^{-1}$. These features demonstrate that the PA-COF flexible supercapattery has potential in energy storage and wearable electronics applications.
We have synthesized a new phenanthroline covalent organic framework (PA-COF) and evaluated it as a cathode material for an aqueous zinc ion supercapattery (ZIS). The assynthesized PA-COF delivers a high capacity of $247 \mathrm{mAh}$ $\mathrm{g}^{-1}$ at a current density of $0.1 \mathrm{~A} \mathrm{~g}^{-1}$. Furthermore, the COF cathode shows an average capacity decay of only $0.38 \%$ per cycle during 10000 cycles at a current density of $1.0 \mathrm{~A} \mathrm{~g}^{-1}$. We confirmed the cointercalation mechanism of $\mathrm{Zn}^{2+} / \mathrm{H}^{+}$by electrochemical analysis and ${ }^{2} \mathrm{D}$ solid-state NMR, in which the capacity contribution of $\mathrm{Zn}^{2+}$ and $\mathrm{H}^{+}$was quantitatively analyzed. In addition, the function of the phenanthroline unit was identified to serve as the active ion-binding sites in PA$\mathrm{COF}$ through the experimental analysis and theoretical simulations. We believe that our new COF design strategy opens a new direction for COF electrodes in aqueous ion batteries.

\section{ASSOCIATED CONTENT}

\section{Supporting Information}

The Supporting Information is available free of charge at https://pubs.acs.org/doi/10.1021/acsenergylett.0c00903.

Experimental section, Figures S1-S13, and Tables S1S4 (PDF)

Video S1 (MP4)

\section{AUTHOR INFORMATION}

\section{Corresponding Authors}

Mohamed Eddaoudi - Advanced Membranes and Porous Materials Center, Physical Science and Engineering Division, Functional Materials Design, Discovery and Development, King Abdullah University of Science and Technology (KAUST), Thuwal 23955-6900, Saudi Arabia; 이이.dorg/0000-00031916-9837; Email: mohamed.eddaoudi@kaust.edu.sa

Husam N. Alshareef - Materials Science and Engineering, Physical Science and Engineering Division, King Abdullah University of Science and Technology (KAUST), Thuwal 23955-6900, Saudi Arabia; (1) orcid.org/0000-0001-50292142; Email: husam.alshareef@kaust.edu.sa

\section{Authors}

Wenxi Wang - Materials Science and Engineering, Physical Science and Engineering Division, King Abdullah University of Science and Technology (KAUST), Thuwal 23955-6900, Saudi Arabia; (1) orcid.org/0000-0002-7088-0539

Vinayak S. Kale - Advanced Membranes and Porous Materials Center, Physical Science and Engineering Division, Functional Materials Design, Discovery and Development, King Abdullah University of Science and Technology (KAUST), Thuwal 23955-6900, Saudi Arabia; 이이.org/0000-0001-78690660

Zhen Cao - Materials Science and Engineering, Physical Science and Engineering Division, King Abdullah University of Science and Technology (KAUST), Thuwal 23955-6900, Saudi Arabia

Sharath Kandambeth - Advanced Membranes and Porous Materials Center, Physical Science and Engineering Division, Functional Materials Design, Discovery and Development, King Abdullah University of Science and Technology (KAUST), Thuwal 23955-6900, Saudi Arabia

Wenli Zhang - Materials Science and Engineering, Physical Science and Engineering Division, King Abdullah University of Science and Technology (KAUST), Thuwal 23955-6900, Saudi Arabia; (1) orcid.org/0000-0002-6781-2826 
Jun Ming - State Key Laboratory of Rare Earth Resource Utilization, Changchun Institute of Applied Chemistry, CAS, Changchun 130022, PR China; (1) orcid.org/0000-00019561-5718

Prakash T. Parvatkar - Advanced Membranes and Porous Materials Center, Physical Science and Engineering Division, Functional Materials Design, Discovery and Development, King Abdullah University of Science and Technology (KAUST), Thuwal 23955-6900, Saudi Arabia

Edy Abou-Hamad - Core Laboratories, King Abdullah University of Science and Technology (KAUST), Thuwal 23955-6900, Saudi Arabia

Osama Shekhah - Advanced Membranes and Porous Materials Center, Physical Science and Engineering Division, Functional Materials Design, Discovery and Development, King Abdullah University of Science and Technology (KAUST), Thuwal 23955-6900, Saudi Arabia; 이이이.org/0000-0003-18619226

Luigi Cavallo - Materials Science and Engineering, Physical Science and Engineering Division, King Abdullah University of Science and Technology (KAUST), Thuwal 23955-6900, Saudi Arabia; O orcid.org/0000-0002-1398-338X

Complete contact information is available at: https://pubs.acs.org/10.1021/acsenergylett.0c00903

\section{Author Contributions}

${ }^{\ddagger}$ W.W., V.S.K., and Z.C. contributed equally to this work.

\section{Notes}

The authors declare no competing financial interest.

\section{ACKNOWLEDGMENTS}

Research reported in this publication was supported by King Abdullah University of Science and Technology (KAUST) under Award Number OSR-CRG2017-3379.

\section{REFERENCES}

(1) Ming, J.; Guo, J.; Xia, C.; Wang, W.; Alshareef, H. N. Zinc-ion Batteries: Materials, Mechanisms, and Applications. Mater. Sci. Eng., $R$ 2019, 135, 58-84.

(2) Chen, L.; An, Q.; Mai, L. Recent Advances and Prospects of Cathode Materials for Rechargeable Aqueous Zinc-Ion Batteries. Adv. Mater. Interfaces 2019, 6 (17), 1900387.

(3) Song, M.; Tan, H.; Chao, D. L.; Fan, H. J. Recent Advances in Zn-Ion Batteries. Adv. Funct. Mater. 2018, 28, 1802564.

(4) Pan, H.; Shao, Y.; Yan, P.; Cheng, Y.; Han, K. S.; Nie, Z.; Wang, C.; Yang, J.; Li, X.; Bhattacharya, P.; Mueller, K. T.; Liu, J. Reversible Aqueous Zinc/manganese Oxide Energy Storage from Conversion Reactions. Nat. Energy 2016, 1 (5), 16039.

(5) Huang, J.; Wang, Z.; Hou, M.; Dong, X.; Liu, Y.; Wang, Y.; Xia, Y. Polyaniline-intercalated Manganese Dioxide Nanolayers as A Highperformance Cathode Material for An Aqueous Zinc-ion battery. Nat. Commun. 2018, 9 (1), 2906.

(6) Kundu, D.; Adams, B. D.; Duffort, V.; Vajargah, S. H.; Nazar, L. F. A High-Capacity and Long-life Aqueous Rechargeable Zinc Battery Using A Metal Oxide Intercalation Cathode. Nat. Energy 2016, 1 (10), 16119.

(7) He, P.; Yan, M.; Zhang, G.; Sun, R.; Chen, L.; An, Q.; Mai, L. Layered $\mathrm{VS}_{2}$ Nanosheet-Based Aqueous $\mathrm{Zn}$ Ion Battery Cathode. Adv. Energy Mater. 2017, 7 (11), 1601920.

(8) Ming, F.; Liang, H.; Lei, Y.; Kandambeth, S.; Eddaoudi, M.; Alshareef, $\mathrm{H}$. N. Layered $\mathrm{Mg}_{\mathrm{x}} \mathrm{V}_{2} \mathrm{O}_{5} \cdot \mathrm{nH}_{2} \mathrm{O}$ as Cathode Material for High-Performance Aqueous Zinc Ion Batteries. ACS Energy Lett. 2018, 3 (10), 2602-2609.
(9) Zhang, L.; Chen, L.; Zhou, X.; Liu, Z. Towards High-Voltage Aqueous Metal-Ion Batteries Beyond 1.5 V: The Zinc/Zinc Hexacyanoferrate System. Adv. Energy. Mater. 2015, 5 (2), 1400930.

(10) Diercks, C. S.; Yaghi, O. M. The Atom, The Molecule, and The Covalent Organic Framework. Science 2017, 355, eaal1585.

(11) Rodriguez-San-Miguel, D.; Zamora, F. Processing of Covalent Organic Frameworks: An Ingredient for A Material to Succeed. Chem. Soc. Rev. 2019, 48 (16), 4375-4386.

(12) Xu, S.; Wang, G.; Biswal, B. P.; Addicoat, M.; Paasch, S.; Sheng, W.; Zhuang, X.; Brunner, E.; Heine, T.; Berger, R.; Feng, X. A Nitrogen-Rich 2D sp(2) -Carbon-Linked Conjugated Polymer Framework as A High-Performance Cathode for Lithium-Ion Batteries. Angew. Chem., Int. Ed. 2019, 58 (3), 849-853.

(13) Cote, A. P.; Benin, A. I.; Ockwig, N. W.; O’Keeffe, M.; Matzger, A. J.; Yaghi, O. M. Porous, Crystalline, Covalent Organic Frameworks. Science 2005, 310 (5751), 1166-1170.

(14) Huang, N.; Wang, P.; Jiang, D. Covalent Organic Frameworks: A Materials Platform for Structural and Functional Designs. Nat. Rev. Mater. 2016, 1 (10), 16068.

(15) Kandambeth, S.; Dey, K.; Banerjee, R. Covalent Organic Frameworks: Chemistry beyond the Structure. J. Am. Chem. Soc. 2019, 141 (5), 1807-1822.

(16) Gu, S.; Wu, S.; Cao, L.; Li, M.; Qin, N.; Zhu, J.; Wang, Z.; Li, Y.; Li, Z.; Chen, J.; Lu, Z. Tunable Redox Chemistry and Stability of Radical Intermediates in 2D Covalent Organic Frameworks for High Performance Sodium Ion Batteries. J. Am. Chem. Soc. 2019, 141 (24), 9623-9628.

(17) Jeong, K.; Park, S.; Jung, G. Y.; Kim, S. H.; Lee, Y. H.; Kwak, S. K.; Lee, S. Y. Solvent-Free, Single Lithium-Ion Conducting Covalent Organic Frameworks. J. Am. Chem. Soc. 2019, 141 (14), 5880-5885.

(18) Luo, Z.; Liu, L.; Ning, J.; Lei, K.; Lu, Y.; Li, F.; Chen, J. A Microporous Covalent-Organic Framework with Abundant Accessible Carbonyl Groups for Lithium-Ion Batteries. Angew. Chem., Int. Ed. 2018, 57 (30), 9443-9446.

(19) Xu, J.; He, Y.; Bi, S.; Wang, M.; Yang, P.; Wu, D.; Wang, J.; Zhang, F. An Olefin-Linked Covalent Organic Framework as A Flexible Thin-Film Electrode for a High-Performance Micro-Supercapacitor. Angew. Chem., Int. Ed. 2019, 58 (35), 12065-12069.

(20) Zhong, W.; Sa, R.; Li, L.; He, Y.; Li, L.; Bi, J.; Zhuang, Z.; Yu, Y.; Zou, Z. A Covalent Organic Framework Bearing Single Ni Sites as a Synergistic Photocatalyst for Selective Photoreduction of $\mathrm{CO} 2$ to CO. J. Am. Chem. Soc. 2019, 141 (18), 7615-7621.

(21) Ding, S. Y.; Gao, J.; Wang, Q.; Zhang, Y.; Song, W. G.; Su, C. Y.; Wang, W. Construction of Covalent Organic Framework for Catalysis: Pd/COF-LZU1 in Suzuki-Miyaura Coupling Reaction. J. Am. Chem. Soc. 2011, 133 (49), 19816-19822.

(22) Rao, M. R.; Fang, Y.; De Feyter, S.; Perepichka, D. F. Conjugated Covalent Organic Frameworks via Michael AdditionElimination. J. Am. Chem. Soc. 2017, 139 (6), 2421-2427.

(23) Furukawa, H.; Yaghi, O. M. Storage of Hydrogen, Methane, and Carbon Dioxide in Highly Porous Covalent Organic Frameworks for Clean Energy Applications. J. Am. Chem. Soc. 2009, 131 (25), $8875-8883$

(24) Khayum M, A.; Ghosh, M.; Vijayakumar, V.; Halder, A.; Nurhuda, M.; Kumar, S.; Addicoat, M.; Kurungot, S.; Banerjee, R. Zinc Ion Interactions in A Two-Dimensional Covalent Organic Framework Based Aqueous Zinc Ion Battery. Chem. Sci. 2019, 10, 8889.

(25) Wang, X.; Chen, L.; Lu, F.; Liu, J.; Chen, X.; Shao, G. Boosting Aqueous $\mathrm{Zn}^{2+}$ Storage in 1,4,5,8-Naphthalenetetracarboxylic Dianhydride through Nitrogen Substitution. ChemElectroChem 2019, 6 (14), 3644-3647.

(26) Zhang, H.; Liu, Q.; Fang, Y.; Teng, C.; Liu, X.; Fang, P.; Tong, Y.; Lu, X. Boosting Zn-Ion Energy Storage Capability of Hierarchically Porous Carbon by Promoting Chemical Adsorption. Adv. Mater. 2019, 31, 1904948.

(27) Segura, J. L.; Juarez, R.; Ramos, M.; Seoane, C. Hexaazatriphenylene (HAT) Derivatives: from Synthesis to Molecular Design, 
Self-organization and Device Applications. Chem. Soc. Rev. 2015, 44 (19), 6850-85.

(28) Kou, Y.; Xu, Y.; Guo, Z.; Jiang, D. Supercapacitive Energy Storage and Electric Power Supply Using An Aza-fused pi-conjugated Microporous Framework. Angew. Chem., Int. Ed. 2011, 50 (37), 8753-7.

(29) Simpson, M. J.; Simpson, A. J. NMR of Soil Organic Matter. In Encyclopedia of Spectroscopy and Spectrometry, 3rd ed.; Lindon, J. C., Tranter, G. E., Koppenaal, D. W., Eds.; Academic Press: Oxford, 2017; pp 170-174.

(30) Shin, J.; Choi, D. S.; Lee, H. J.; Jung, Y.; Choi, J. W. Hydrated Intercalation for High-Performance Aqueous Zinc Ion Batteries. Adv. Energy Mater. 2019, 9 (14), 1900083.

(31) Uysal, A.; Tuncer, D.; Kir, E.; Koseoglu, T. S. Recovery of Nutrients from Digested Sludge as Struvite with A Combination Process of Acid Hydrolysis and Donnan dialysis. Water Sci. Technol. 2017, 76 (10), 2733-2741.

(32) Wang, X.; Bommier, C.; Jian, Z.; Li, Z.; Chandrabose, R. S.; Rodriguez-Perez, I. A.; Greaney, P. A.; Ji, X. Hydronium-ion Batteries with Perylenetetracarboxylic Dianhydride Crystals as An Electrode. Angew. Chem., Int. Ed. 2017, 56 (11), 2909-2913.

(33) Li, W.; Wang, K.; Cheng, S.; Jiang, K. An Ultrastable Presodiated Titanium Disulfide Anode for Aqueous "Rocking-Chair" Zinc Ion Battery. Adv. Energy Mater. 2019, 9 (27), 1900993.

(34) Xia, C.; Guo, J.; Lei, Y.; Liang, H.; Zhao, C.; Alshareef, H. N. Rechargeable Aqueous Zinc-Ion Battery Based on Porous Framework Zinc Pyrovanadate Intercalation Cathode. Adv. Mater. 2018, 30 (5), 1705580.

(35) Wang, J.; Polleux, J.; Lim, J.; Dunn, B. Pseudocapacitive Contributions to Electrochemical Energy Storage in $\mathrm{TiO}_{2}$ (Anatase) Nanoparticles. J. Phys. Chem. C 2007, 111 (40), 14925-14931.

(36) Mathis, T. S.; Kurra, N.; Wang, X.; Pinto, D.; Simon, P.; Gogotsi, Y. Energy Storage Data Reporting in Perspective-Guidelines for Interpreting the Performance of Electrochemical Energy Storage Systems. Adv. Energy Mater. 2019, 9, 1902007.

(37) Zhang, X.; Luo, X.; Zheng, X.; Wu, X.; Xu, H. Protonationassisted Exfoliation of N-Containing 2D Conjugated Polymers. Small 2019, 15, 1903643. 